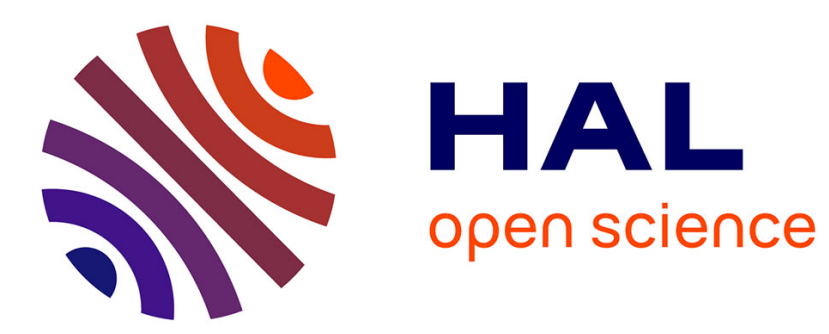

\title{
Reliability of health-related physical fitness tests in adolescents: the MOVE Program
}

Jeremy Vanhelst, Laurent Beghin, Paul S Fardy, Zekya Ulmer, Gregory Czaplicki

\section{- To cite this version:}

Jeremy Vanhelst, Laurent Beghin, Paul S Fardy, Zekya Ulmer, Gregory Czaplicki. Reliability of health-related physical fitness tests in adolescents: the MOVE Program. Clinical Physiology and Functional Imaging, 2016, 36 (2), pp.106-111. 10.1111/cpf.12202 . hal-02177635

\section{HAL Id: hal-02177635 \\ https://hal.univ-lille.fr/hal-02177635}

Submitted on 9 Jul 2019

HAL is a multi-disciplinary open access archive for the deposit and dissemination of scientific research documents, whether they are published or not. The documents may come from teaching and research institutions in France or abroad, or from public or private research centers.
L'archive ouverte pluridisciplinaire HAL, est destinée au dépôt et à la diffusion de documents scientifiques de niveau recherche, publiés ou non, émanant des établissements d'enseignement et de recherche français ou étrangers, des laboratoires publics ou privés. 
Reliability of health-related physical fitness tests in adolescents: The Move

\section{Program}

Jérémy Vanhelst ${ }^{1-2}$, Laurent Béghin ${ }^{1-2}$, Paul S. Fardy ${ }^{3}$, Zekya Ulmer $^{4}$, Grégory Czaplicki $i^{5-6}$

\footnotetext{
${ }^{1}$ Inserm U995, Université Lille Nord de France, Lille, France

${ }^{2}$ CIC-PT-1403-Inserm-CH\&U, Lille, France

${ }^{3}$ Professor Emeritus, Queens College, City University of New York, Flushing, NY

${ }^{4}$ Fédération Nationale de Mutualité Française, Paris, France

${ }^{5}$ Mutualité Ile de France, Paris, France

${ }^{6}$ GIRAS, UQTR, Trois-Rivières, Canada
}

Auteur correspondant: J. Vanhelst

Antenne pédiatrique du CIC

Hôpital Jeanne de Flandre

CHRU de Lille

Avenue Eugène Avinée

59000 Lille Cedex

Tel: +33 320446058

Fax: +33 320446687

E-mail: jeremy.vanhelst@chru-lille.fr

Short Title: Reliability of fitness tests 


\begin{abstract}
The aim was to examine the reliability of health-related physical fitness tests that were used in a French health promotion program "Move... A priority for your health". Participants were 174 French youth (88 children and 86 adolescents) ages 8.2 to 16.2 years. Aerobic fitness, muscular strength, speed and flexibility were tested using 20$\mathrm{m}$ shuttle run test, $1 / 2$ mile run test, basketball throw, standing long jump, shoulder stretch and 20/30/50-m sprint tests. Reliability was calculated for the basketball throw, standing long jump, shoulder stretch and sprint tests. The tests were performed two times, one week apart on the same day of the week. Reliability was examined with Intraclass correlation coefficients (ICCs) and Bland - Altman analysis. With the exception of the $1 / 2$ mile run test, which resulted in moderate agreement (0.66), all tests had high reliability. ICC were $0.97,0.93,0.91$ and 0.93 for the sprint test, basketball throw, shoulder stretch and the standing long jump, respectively. The differences obtained between the first and the second trial were non-significant. Results from this study indicate that the BOUGE health-related physical fitness battery, administrated by physical education teachers, were reliable for measuring health-related components of fitness in children and adolescents in a school setting.
\end{abstract}

Keywords: Assessment, Youth, Aerobic fitness, Muscular strength, Speed, Flexibility, Reproducibility 


\section{Introduction}

Physical fitness is an important determinant of health in children and adolescents (Ortega et al., 2008). Health-related physical fitness includes muscular strength (lower and upper limbs), flexibility, speed/agility, and cardiorespiratory fitness (Heyward, 1991). Positive health-related physical fitness in childhood and adolescence helps to prevent mental, nutritional, gastroenterological, cardiac, and respiratory diseases (Ortega et al., 2008).

Health-related physical fitness tests are administered in the laboratory and in the field. Laboratory testing generally has the advantage of high validity and reliability (Heyward, 1991). The disadvantage, however, is that laboratory assessment requires trained personnel, is time consuming, and necessitates costly equipment. Field tests generally are easier to administer, require less time and utilise less expensive equipment (Heyward, 1991).

The French national program "Move... A priority for your health" (http://www.bougetasante.fr/), aims to assess the levels of physical fitness in youth, ages 6 to 18 years, in their school environment. For this purpose, a set of healthrelated physical fitness field tests was chosen (http://www.bougetasante.fr/). Field tests were chosen for the study because they: (i) are easy to administer by a physical education teacher; (ii) involve minimal equipment at low cost; (iii) are safe; (iv) are easily adapted according to age; and, (v) can assess health-related physical fitness in a short period of time.

The tests selected to measure health related physical fitness included the $20-\mathrm{m}$ shuttle run test, $1 / 2$ mile test, basketball throw, standing long jump, 20/30/50-m sprint tests, and the shoulder stretch test. The rationale for selecting these tests has been described elsewhere (Vanhelst et al., 2014). Validity refers to the ability of the test to 
reflect what it is designed to measure (Artero et al., 2011; Ortega et al., 2008). The validity of a tool is judged by comparison with a 'gold standard' method. Reliability refers to the reproducibility of values of a test in repeated trials on the same individual (Artero et al., 2011; Ortega et al., 2008).

The tests, included in the MOVE program, have been previously validated in youth (Castro-Piñero et al., 2013; Castro-Piñero et al., 2010; Castro-Piñero et al., 2009; Castro-Piñero et al., 2010; Castro-Piñero et al., 2009; Léger \& Cadoury, 1989). However, the reliability of physical fitness tests is also necessary. Only, the reliability of the shuttle run test was widely assessed (Artero et al., 2011; Ortega et al., 2008). Reliability for the other field tests used in the program have not been well studied (Artero et al., 2011; Ortega et al., 2008).

The aim of this study was to assess the reliability of health-related physical fitness field tests used in the "Move... A priority for your health" program among children and adolescents.

\section{Methods}

Study design

This ancillary study is based on the French health promotion program "Move... A priority for your health" (http://www.bougetasante.fr/). The principal aim of this program is to promote the benefits of physical activity and physical fitness on the health of French youth, ages 6 to 18 years. The program will be performed in many classes throughout France. All data obtained from the organiser (Mutualité Française) of the event were anonymous, declared to the CNIL (Commission Nationale de l'Informatique et des Libertés). The aims and objectives were explained carefully to each adolescent and to parents. After this explanation, adolescents and 
parents could accept or decline to participate to this study and to record anonymously their information technology data. This study obtained an agreement by the local research ethics committee (Comité de Protection des Personnes Nord Ouest IV, Lille, France), and all procedures were performed in accordance with the ethical standards of the Helsinki Declaration of 1975 (as revised in 2008) and the European Good Clinical Practice Guidelines.

A manual of operations (rational of the study, procedures of tests, and how recorded the data) was designed for and read by the physical education teacher involved in the health promotion program before the data collection started. Instructions provided to the participants were described in the manual of operations in order to standardize procedures.

Eighty-eight children, ages 6 to 11.9, and 86 adolescents, ages 12 to 16 years participated in this study in order to assess reliability of the physical fitness tests. Participants were asked to perform each test two times. Tests were scheduled one week apart. Retesting was performed at the same time of day to minimize circadian rhythm variability.

\section{Anthropometric measurements}

Weight was measured in shorts and T-shirts without shoes to the nearest $0.1 \mathrm{~kg}$ using an electronic scale (Oregon Scientific, GA 101, USA). Height was measured without shoes to the nearest $0.1 \mathrm{~cm}$ using a standard physician's scale.

\section{Physical fitness assessment}

1- Sprint test: the participant stands in stationery and comfortable position, feet behind the starting line, with no rocking movements. Runners were instructed to start 
on the whistle sound, and timers were instructed to start the stopwatch at the whistle sound and stop their stopwatch when the runner crossed the finish line. The test assesses speed (Castro-Piñero et al., 2010).

2- Basketball throw: holding the ball the participant stands at a line with feet slightly apart, facing the direction in which the ball is to be thrown with two hands. The ball is brought back behind the head and thrown as far as possible. The throwing action is similar to that used for a soccer/football sideline throw-in. The participant is encouraged to use the legs, back, and arms to assist in maximizing the distance thrown. The participant is not permitted to fall forward over the line and the feet must remain on the ground before, during, and after the throw. The distance from the starting line to where the ball landed was recorded in centimetres. The best of two attempts was recorded. This test assesses upper-body muscular strength (CastroPiñero et al., 2009).

3- Shoulder stretch test: to test the right shoulder the participant reaches with the right hand over the right shoulder and down the back as if to pull up a zipper or scratch between the shoulder blades. At the same time the participant places the left hand behind the back and reaches up, trying to touch the fingers of the right hand. To test the left shoulder, the participant will do the same but reversing the arm positions. A 0 score is recorded when the participant touches the fingers. If the participant exceeds this line, the tester measures with the distance in centimetres and records a positive number. If the participant cannot touch the finger, the tester measures the distance between fingers and records a negative number. This test assesses shoulder flexibility (Castro-Piñero et al., 2013). 
4- Standing long jump: in a standing position immediately behind a line and feet shoulder's width apart, the participant jumps as far as possible with feet together. A non-slip hard surface, chalk and a tape measure were used to perform the test. Distance is recorded in centimetres. This test assesses the lower-body muscular strength (Ortega et al., 2008).

5-1/2-mile run/walk test: the participant was instructed and encouraged to complete the distance as fast as possible. Walking was permitted if the subject was unable to run the entire distance. Time was recorded to the nearest second. This test assesses cardiorespiratory fitness (Castro-Piñero et al., 2011).

\section{Statistical analysis}

The data were analysed using the Statistical Package for the Social Sciences, Windows v. 11.5 (SPSS Inc., Chicago, IL) and Excel 2003 (Microsoft Inc., Redmond, WA). Data are expressed as mean (standard deviation). The level of significance was $\mathrm{p}<0.05$.

Reliability between test-retest was assessed using the intraclass correlation coefficient (ICC) according to the Fleiss method (Fleiss, 1986). The ICC was interpreted as follows: $0-0.2$ indicates poor agreement; $0.3-0.4$ indicates fair agreement; $0.5-0.6$ indicates moderate agreement; $0.7-0.8$ indicates strong agreement; and 0.8 indicates almost perfect agreement (13). Reliability was also assessed according to the method of Bland \& Altman (1986). The analysis measures bias as estimated from mean differences, the $95 \%$ confidence interval for bias, and the limits of agreement, \pm 2 standard deviations of the difference. 
A dependent $t$-test was performed to determine whether there were significant differences between the scores performed by boys and girls.

\section{Results}

One hundred seventy-four youth participated in the study. Mean age was $11.6 \pm$ 2.1 years (range: $8.2-16.2$ ). Physical characteristics of the participants are presented in Table 1.

\section{Insert Table 1}

\section{Sprint tests}

Time for the two tests was $5.32 \pm 1.4 \mathrm{sec}$ and $5.13 \pm 1.35 \mathrm{sec}$, respectively (Table 2). Children have significantly better scores $(p<0.001)$ than adolescents $(4.48 \pm 0.67$ vs $5.8 \pm 1.54 \mathrm{sec})$. The intraclass correlation coefficient between the two trials was high (children and adolescents) demonstrating good reliability (Table 2). The high concordance of the intraclass correlation between times obtained in the two sprint tests is reinforced by the Bland and Altman method.

Mean differences were within the limits of Bland and Altman and most data points were within the limits of agreement of bias (Figure 1). The mean difference was very near to $0(-0.16 \pm 0.35)$ seconds, and the limits of agreement were -0.88 to 0.54

Basketball throw 
Throwing distances for the two trials were $858.9 \pm 244.2$ and $845.5 \pm 238.5 \mathrm{~cm}$, respectively (Table 2). Significant differences were obtained according to age $(p<$ 0.001), with adolescents throwing farther than children $(969.9 \pm 250.9$ vs $750.5 \pm$ 181.6 meters). In each age range, the intraclass correlation coefficient between the two basketball throw tests was high demonstrating good reliability (Table 2). The Bland and Altman method confirmed the results obtained from intraclass correlation.

Mean differences were within the limits of Bland and Altman and most data points were within the limits of agreement of bias (Figure 2). The mean difference was very near to $0(-18.3 \pm 158.6)$ meters, and the limits of agreement were -335.6 to 298.9

\section{Shoulder stretch test}

The scores for the two shoulder stretch test were $6.1 \pm 6.8 \mathrm{~cm}$, and $6.9 \pm 7.1 \mathrm{~cm}$, respectively (Table 2$)$. Adolescents had significantly $(\mathrm{p}<0.001)$ better test results than children, $(8.4 \pm 6.9$ vs $5.5 \pm 6.9 \mathrm{~cm})$. The intraclass correlation coefficient between the two trials was high demonstrating good reliability in children and adolescent (Table 2). The high concordance of the intraclass correlation between data obtained in the two tests is reinforced by the Bland \& Altman method.

Mean differences was within the limits of Bland and Altman and most data points were within the limits of agreement of bias (Figure 3). The mean difference was very near to $0(0.9 \pm 2.9) \mathrm{cm}$, and the limits of agreement were -4.9 to 6.6 .

\section{Standing long jump}

Distances for the two jump tests were $174.9 \pm 63.6$ and $177.6 \pm 60.8 \mathrm{~cm}$, respectively (Table 2$)$. Adolescents had significantly $(p<0.001)$ better scores than 
children $(202.2 \pm 63.2$ vs $153.60 \pm 47.5 \mathrm{~cm})$. The intraclass correlation coefficient between the two tests was high in each age range, demonstrating good reliability (Table 2). The Bland and Altman method confirmed the results obtained from the intraclass correlation.

Mean differences were within the limits of Bland and Altman and most data points were within the limits of agreement of bias (Figure 4). The mean difference was very near to $0(1.8 \pm 31.5) \mathrm{cm}$, and the limits of agreement were -61.3 to 64.9.

\section{1/2-mile run/walk tests}

Times for the two run/walk tests were $299.7 \pm 85.4$ and $298.1 \pm 52.2 \mathrm{sec}$, respectively (Table 2). Significant differences were found between age ranges $(\mathrm{p}<$ $0.001)$. Adolescents had significantly $(\mathrm{p}<0.001)$ better scores than children $(277.3 \pm$ 105.3 vs $325.8 \pm 102.3 \mathrm{sec})$. The intraclass correlation coefficient between the two trials was moderate demonstrating acceptable reliability for both age ranges (Table 2).

Mean differences were within the limits of Bland and Altman and most data points were within the limits of agreement of bias (Figure 5). The mean difference was very near to $0(-3.21 \pm 74.9)$ seconds, and the limits of agreement were -153.1 to 146.7 .

\section{Insert Table 2}

\section{Discussion}

The aim of this study was to assess the reliability of different health-related physical fitness field tests used in the MOVE study among children, unexplored or poorly studied (Artero et al., 2011; Ortega et al., 2008). The main finding of our study shows that the Move heath-related fitness battery administrated by physical 
education teachers is reliable for assessing the levels of physical fitness in youth in a school environment.

The Move health-related fitness test includes two tests for assessing cardiorespiratory fitness, the $20-\mathrm{m}$ shuttle run test for adolescents and the $1 / 2$ mile run/walk test for children. Reliability of the 20 -m shuttle run test was not measured as it has been widely studied previously (Artero et al., 2011). Good reliability was found for the shuttle run test in children and adolescents ages 8-18 years (Artero et al., 2011). The intraclass correlation coefficient values varied from 0.78 to 0.93 (Beets \& Pitetti, 2006; Liu et al., 1992; Mahar et al., 1997; Mahar et al.., 1997; Pitetti et al., 2002). Conversely, only one study examined the reliability of the $1 / 2$ mile run/walk test for children ages to 5-9 years (Rikli et al., 1992). Test reliability was acceptable for children ages 8-9 years but decreased with increased age (Rikli et al., 1992). Our findings, in contrast to Rikli et al. (1992), showed better reliability in children (0.71) than adolescents (0.63). Poor reliability for this test in adolescents confirms the choice to use the 20-m shuttle run test for this age range in the Move heath-related fitness battery. The poor reliability may be explained by the lack of fun in the $1 / 2$ mile run/walk test.

We observed a high reliability in standing long jump and the basketball throw tests. Our findings are in agreement with previous results (Ortega et al., 2008b). Ortega et al examined the reliability of the standing long jump in 123 adolescents ages $13.6 \pm 0.8$ years old (Ortega et al., 2008b). Authors concluded that neither a learning nor a fatigue effect was found for the standing long jump test when repeated. In contrast, España-Romero et al. (2010) showed a low reliability in children. Authors explained that low reliability could be due to performance on the day or even learning effects, i.e. positive systematic bias (España-Romero et al., 2010). The 
disagreement between our results and the previous study may be due to a wider age range in the study of España-Romero et al. (2010). For the upper-body muscular strength, there are no data available on the reliability of the basketball throw test. Our results showed a high reliability in children and adolescents, suggesting neither learning nor fatigue (negative systematic bias) effects.

To our knowledge, reliability of the sprint test and the shoulder stretch test have not been previously studied. Although the two tests have been validated (Heyward, 1991; Castro-Piñero et al., 2010), the assessment of the reliability is needed for defining the quality of the test (Currell \& Jeukendrup, 2008). Finally, our study is the first to validate the use of the sprint and the shoulder stretch tests in the assessment of speed and flexibility in children and adolescents.

Physical education teachers were also asked to comment on the feasibility of health-related physical fitness tests. All teachers reported good feasibility in administering the tests included in the BOUGE battery in a school environment. Teachers appreciated the possibility to assess health-related physical fitness with tests requiring low cost, small space, and the possibility to perform either in a gymnasium or on outdoor fields. Results from the French Move battery are in agreement with previous European studies assessing health-related physical fitness tests, i.e. HELENA study and The ALPHA study (Ortega et al., 2008; EspañaRomero et al., 2010).

Because of the high interest in health promotion and intervention programs in children and adolescents, there is a need for adequate age-appropriate measures to test and evaluate improvement of health-related physical fitness in children and adolescents. The results of our study are relevant and practical for practitioners. These tests are chosen for many advantages: they are less expensive, safety, 
involving minimal equipment, easy and quickly to administer, and require little space (i.e. can be performed in school environment or hospital).

In conclusion, our study provides new information on the reliability of field tests not previously studied. Our findings show that the reliability is acceptable for a set of health-related physical fitness field tests used in the Move study among French youth. Adding to the validity of these tests already explored in children and adolescent, our results on the reliability reinforce the interest to use these tests to assess healthrelated physical fitness in school environment.

Further information, including protocols and figures of physical fitness tests, on the health-related physical fitness battery is available in the MOVE website: http://www.prioritesantemutualiste.fr/psm/bouge-ta-sante

\section{Acknowledgements}

The authors thank all participating adolescents and teachers for their collaboration in the study. Authors thank also the association "SportAlim" (www.sportalim.com).

\section{Conflict of Interest statement}

The authors declared no conflict of interest. 


\section{References}

Artero EG, España-Romero V, Castro-Piñero J, Ortega FB, Suni J, Castillo-Garzon MJ,

Ruiz JR. Reliability of field-based fitness tests in youth. Int J Sports Med (2011); 32: 159-169.

Beets MW, Pitetti KH. Criterion-referenced reliability and equivalency between the PACER and 1-mile run/walk for high school students. Measur Phys Educ Exer Sci (2006); 3: S21 - S33

Bland JM, Altman DG. Statistical methods for assessing agreement between two methods of clinical measurement. Lancet (1986); 1:307-310.

Castro-Piñero J, Girela-Réjon MJ, González-Montesinos JL, Mora J, Conde-Caveda J, Sjöström M. Percentile values for flexibility tests in youths aged 6 to 17 years: influence of weight status. Eur J Sport Sci (2013); 13: 139- 148.

Castro-Piñero J, González-Montesinos JL, Keating XD, Mora J, Sjöström M, Ruiz JR. Percentile values for running sprint field tests in children ages 6-17 years: influence of weight status. Res $Q$ Exerc Sport (2010); 81: 143-151.

Castro-Piñero J, González-Montesinos JL, Mora J, Keating XD, Girela-Rejón MJ, Sjöström M, Ruiz JR. Percentile values for muscular strength field tests in children aged 6 to 17 years: influence of weight status. J Strength Cond Res (2009); 23: 2295-2310. 
Castro-Piñero J, Ortega FB, Artero EG, Girela-Rejón MJ, Mora J, Sjöström M, Ruiz JR. Assessing muscular strength in youth: usefulness of standing long jump as a general index of muscular fitness. J Strength Cond Res (2010); 24: 1810-1817.

Castro-Piñero J, Ortega FB, Keating XD, González-Montesinos JL, Sjöström M, Ruiz JR. Percentile values for aerobic performance running/walking field tests in children aged 6 to 17 years; influence of weight status. Nutr Hosp (2011); 26: 572-578.

Castro-Piñero J, Ortega FB, Mora J, Sjöström M, Ruiz JR. Criterion related validity of 1/2 mile run-walk test for estimating $\mathrm{VO}_{2}$ peak in children aged 6-17 years. Int $J$ Sports Med (2009); 30: 366-71.

Currell K, Jeukendrup AE. Validity, reliability and sensitivity of measures of sporting performance. Sports Med (2008); 38: 297-316.

España-Romero V, Artero EG, Jimenez-Pavón D, Cuenca-Garcia M, Ortega FB, Castro-Piñero J, Sjöstrom M, Castillo-Garzon MJ, Ruiz JR. Assessing health-related fitness tests in the school setting: reliability, feasibility and safety; The ALPHA Study. Int J Sports Med (2010); 31: 490-497.

Fleiss JL. Design and Analysis of Clinical Experiments. In New York (eds). New York, NY, USA; 1986

Heyward VH. Advanced fitness assessment and exercise prescription. In: 3e édition. Champain, Illinois, Human Kinetics Books, 1991 
Leger L, Gadoury C. Validity of the $20 \mathrm{~m}$ shuttle run test with $1 \mathrm{~min}$ stages to predict $\mathrm{VO}_{2}$ max in adults. Can J Sport Sci (1989); 14: 21-26.

Liu NY, Plowman SA, Looney MA. The reliability and validity of the 20-meter shuttle test in American students 12 to 15 years old . Res Q Exerc Sport (1992); 63: 360 - 365.

Mahar MT, Parker CR, Rowe DA. Agreement among three fi eld tests of aerobic capacity. Res Q Exerc Sport (1997); 68 : A-54.

Mahar MT , Rowe DA, Parker CR , Mahar FJ , Dawson DM , Holt JE. Criterionreferenced and norm-referenced agreement between the mile run/walk and PACER. Meas Phys Educat Exerc Sci (1997); 1 : 245 - 258.

Ortega FB, Artero EG, Ruiz JR, Vicente-Rodriguez G, Bergman P, Hagströmer M, Ottevaere C, Nagy E, Konsta O, Rey-López JP, Polito A, Dietrich S, Plada M, Béghin L, Manios Y, Sjöström M, Castillo MJ; HELENA Study Group. Reliability of healthrelated physical fitness tests in European adolescents. The HELENA Study. Int J Obes (2008); 32: S49-57.

Ortega FB, Ruiz JR, Castillo MJ, Sjöström M. Physical fitness in childhood and adolescence: a powerful marker of health. Int J Obes (2008); 32: 1-11.

Pitetti KH, Fernhall B , Figoni S. Comparing two regression formulas that predict VO2 peak using the 20-m shuttle run for children and adolescents. Ped Exerc Sci (2002); 2: $125-134$. 
Rikli RE, Petray C, Baumgartner TA. The reliability of distance run tests for children in grades K-4. Res Q Exerc Sport (1992); 63: 270-276.

Vanhelst J, Béghin L, Czaplicki G, Ulmer Z. Physical fitness in children and adolescents: how can it be measured in school environment? The example of the BOUGE-Fitness test battery. Rev Med Brux (2014); In press. 


\section{Legends}

Table 1. Physical characteristics of participants $(n=174)$

Table 2. Reliability of physical fitness tests in youth

Figure 1. Reliability of the sprint test

Figure 2. Reliability of the basketball throw test

Figure 3. Reliability of the shoulder stretch test

Figure 4. Reliability of the standing long jump

Figure 5. Reliability of the 1/2-mile run/walk tests 
Table 1. Physical characteristics of participants $(n=174)$

\begin{tabular}{lcc}
\hline & Children & Adolescents \\
\hline $\mathrm{N}$ & 88 & 86 \\
Age $(y r)$ & $9.8 \pm 0.9$ & $13.3 \pm 1.3$ \\
Height $(\mathrm{cm})$ & $138.7 \pm 23.2$ & $164.1 \pm 10.5$ \\
Weight $(\mathrm{kg})$ & $37.1 \pm 7.7$ & $55.1 \pm 15.9$ \\
\hline
\end{tabular}


Table 2. Reliability of physical fitness tests in youth

\begin{tabular}{|c|c|c|c|c|c|}
\hline & $1^{\text {st }}$ trial & $2^{\text {nd }}$ trial & Mean difference [95\% IC] & $\mathbf{P}$ & ICC \\
\hline \multicolumn{6}{|l|}{ All } \\
\hline Sprint test ( $\mathrm{sec}$ ) & $5.32 \pm 1.40$ & $5.13 \pm 1.35$ & $-0.19[-0.03 ; 0.37]$ & 0.254 & 0.97 \\
\hline Basketball throw $(\mathrm{cm})$ & $858.9 \pm 244.2$ & $845.5 \pm 238.5$ & $-13.4[-0.65 ; 1.04]$ & 0.603 & 0.93 \\
\hline Shoulder stretch test $(\mathrm{cm})$ & $6.1 \pm 6.8$ & $6.9 \pm 7.1$ & $0.8[0.78 ; 0.85]$ & 0.297 & 0.91 \\
\hline Standing broad long jump $(\mathrm{cm})$ & $174.9 \pm 63.6$ & $177.6 \pm 60.8$ & $2.7[2.28 ; 3.12]$ & 0.694 & 0.93 \\
\hline $1 / 2 \mathrm{mile}$ run/walk test $(\mathrm{sec})$ & $299.7 \pm 85.4$ & $298.1 \pm 52.2$ & $-1.6[-3.33 ; 6.53]$ & 0.938 & 0.66 \\
\hline \multicolumn{6}{|l|}{ Children } \\
\hline Sprint test ( $\mathrm{sec})$ & $4.68 \pm 0.88$ & $4.48 \pm 0.67$ & $-0.2[0.15 ; 0.25]$ & 0.339 & 0.95 \\
\hline Basketball throw $(\mathrm{cm})$ & $750.5 \pm 181.6$ & $761.6 \pm 186.2$ & $11.1[10.14 ; 12.06]$ & 0.689 & 0.90 \\
\hline Shoulder stretch test $(\mathrm{cm})$ & $4.5 \pm 6.6$ & $5.5 \pm 6.9$ & $1.03[0.97 ; 1.09]$ & 0.313 & 0.93 \\
\hline Standing broad long jump $(\mathrm{cm})$ & $150.3 \pm 45.1$ & $153.6 \pm 47.5$ & $3.3[2.79 ; 3.80]$ & 0.636 & 0.96 \\
\hline $1 / 2$ mile run/walk test $(\mathrm{sec})$ & $325.8 \pm 102.3$ & $335.5 \pm 98.6$ & $9.7[8.93 ; 10.47]$ & 0.208 & 0.71 \\
\hline \multicolumn{6}{|l|}{ Adolescents } \\
\hline Sprint test (sec) & $5.98 \pm 1.54$ & $5.80 \pm 1.54$ & $-0.18[0.16 ; 0.20]$ & 0.621 & 0.96 \\
\hline Basketball throw $(\mathrm{cm})$ & $969.9 \pm 250.9$ & $932.3 \pm 256.1$ & $-37.6[36.5 ; 38.70]$ & 0.333 & 0.93 \\
\hline Shoulder stretch test $(\mathrm{cm})$ & $7.9 \pm 6.6$ & $8.4 \pm 6.9$ & $0.5[0.44 ; 0.56]$ & 0.635 & 0.88 \\
\hline Standing broad long jump $(\mathrm{cm})$ & $200.6 \pm 69.9$ & $202.2 \pm 63.2$ & $1.6[0.18 ; 3.01]$ & 0.872 & 0.89 \\
\hline $1 / 2$ mile run/walk test $(\mathrm{sec})$ & $277.3 \pm 105.3$ & $287.3 \pm 106.1$ & $10.1[9.93 ; 10.27]$ & 0.836 & 0.63 \\
\hline
\end{tabular}




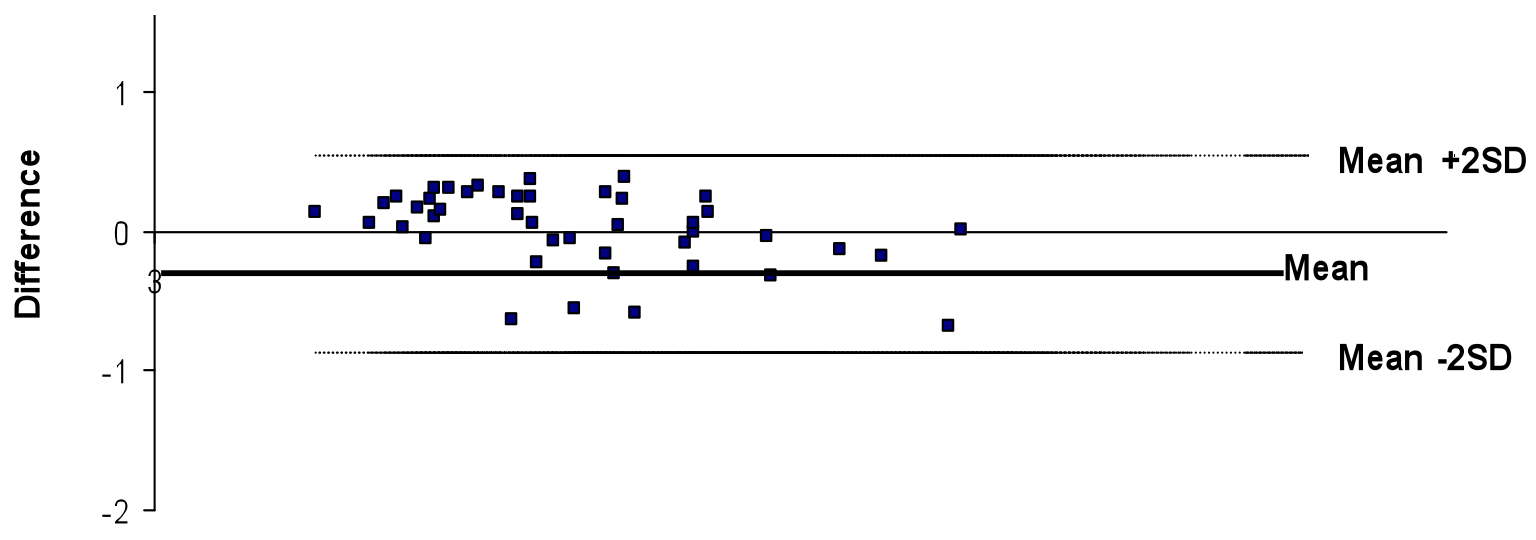

Figure 1. Reliability of the sprint test 


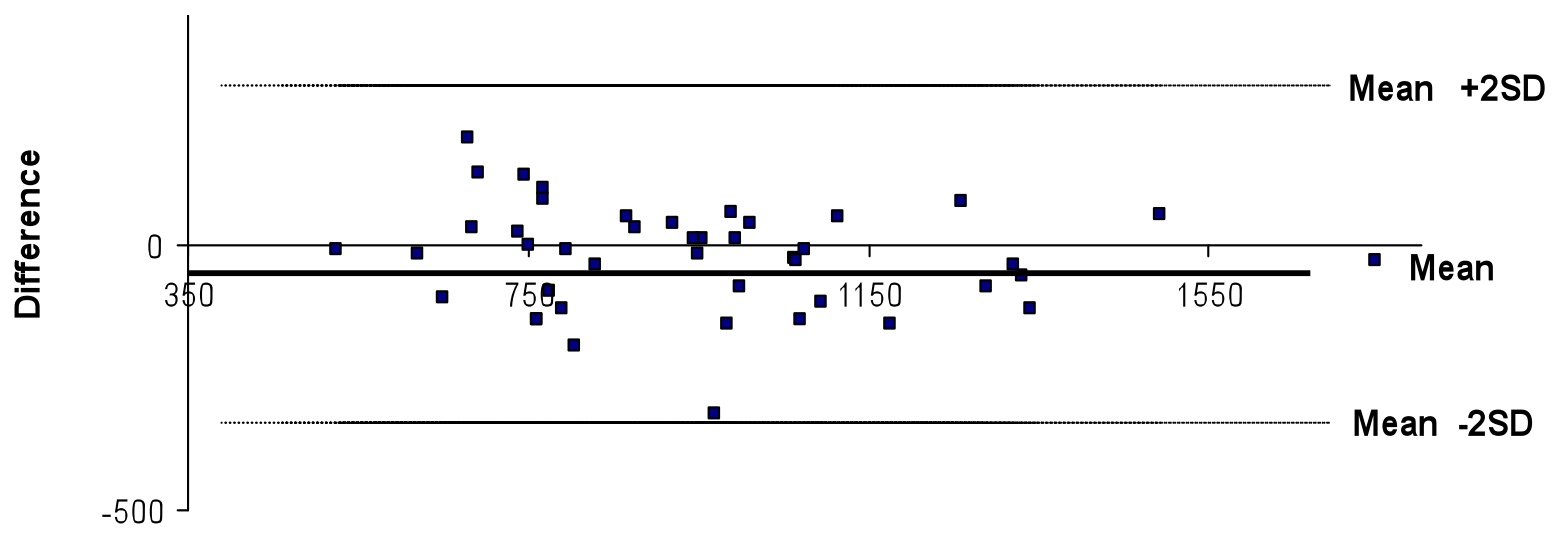

Figure 2. Reliability of the basketball throw test 


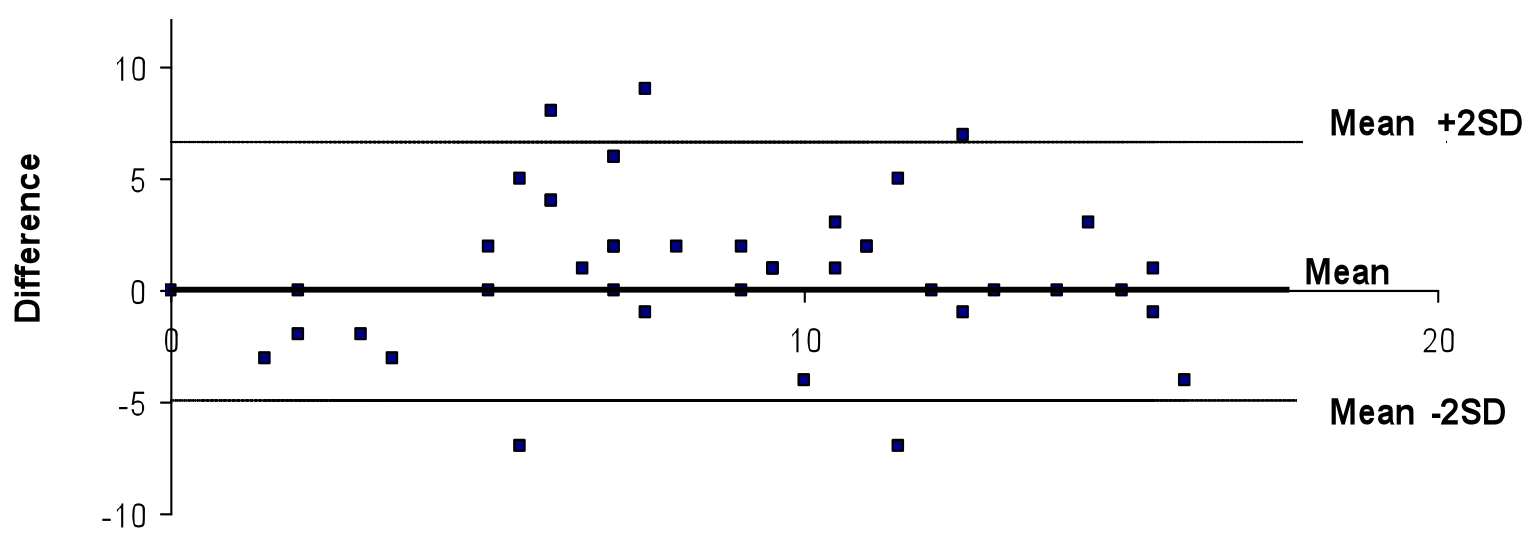

Figure 3. Reliability of the shoulder stretch test 


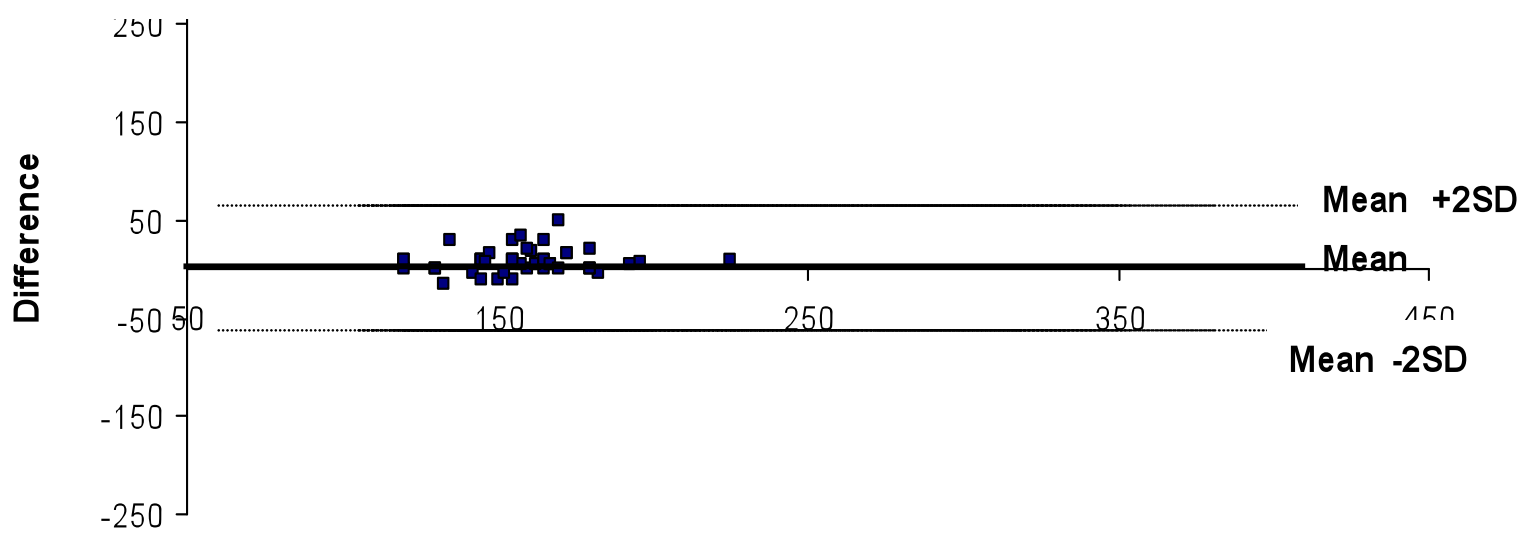

Figure 4. Reliability of the standing long jump 


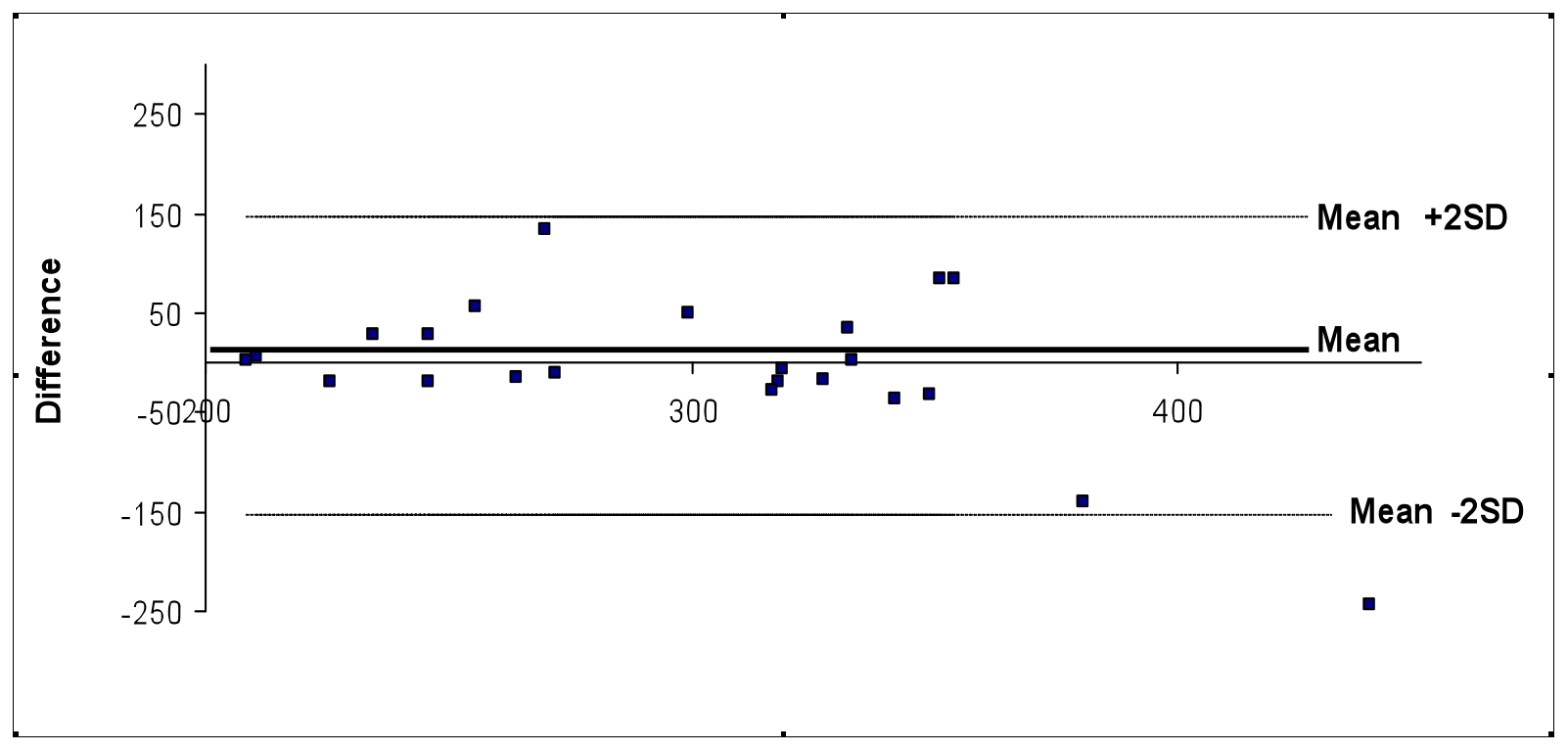

Figure 5. Reliability of the 1/2-mile run/walk tests 